\title{
Significante versus inconsciente, contra-dicções \\ Ou, antes do signo, a o-posição; no início, a imagem
}

\author{
Manuel Moreira da Silva ${ }^{1}$
}

\begin{abstract}
RESUMO: Este trabalho discute a proposição lacaniana segundo a qual "o inconsciente é estruturado como uma linguagem" e sua fundamentação a partir da Antropologia de Lévi-Strauss. Em vista disso, discute o estatuto do significante (no quadro teórico do signo linguístico) como ser concreto e como representação vazia ou indeterminada, destituída de conteúdo ou significado e o da imagem fundante do mesmo, a qual se impõe como seu pressuposto essencial. Enfim, considera os limites e as contradições do significante para a tematização e a compreensão do inconsciente.

Palavras-chave: Lacan, Freud, Lévi-Strauss, Linguagem, Unbegriff
\end{abstract}

ABSTRACT: This paper discusses the Lacanian proposition according to which "the unconscious is structured as a language" and its foundation from the Levi-Strauss Anthropology. In view of this, it discusses the status of the signifier (in the theoretical framework of the linguistic sign) as a concrete being and as an empty or indeterminate representation, devoid of content or meaning and that of the founding image of the same, which is imposed as its essential presupposition. Finally, consider the limits and contradictions of the signifier for thematization and understanding of the unconscious.

Key-words: Lacan, Freud, Lévi-Strauss, Language, Unbegriff

\section{Considerações preliminares}

Este trabalho verifica, de modo provisório, a tese fundamental da assim chamada primeira clínica ${ }^{2}$ de Lacan, a saber, a proposição de que "o inconsciente é estruturado como uma linguagem", tal como apresentada em Le Séminaire, XI. Les quatre concepts fondamentaux de la psychanalyse (1964) $)^{3}$. Tese assim considerada pelo fato de o psicanalista tomá-la como ponto de partida da Psicanálise como ciência e, com isso, da dedução da topologia por ele proposta, "cuja finalidade é dar conta da constituição do sujeito" (Lacan 1973, p. 185). Conforme o francês, "se a Psicanálise deve se constituir como ciência do inconsciente", e, portanto, igualmente da constituição do sujeito, "convém partir de que o inconsciente é estruturado como uma linguagem" (ibid.). O trabalho investiga, pois, a estrutura dialética dessa tese: a contradição cujos extremos são, de um lado, a emergência do sujeito e, de outro, seu congelamento; respectivamente, a contradição de seu ser concreto e de sua representação (Vorstellung), em rigor, da função referencial desta por meio de um representante (Repräsentaz), logo, de um representante

\footnotetext{
${ }^{11}$ Psicanalista, analista didata e docente vinculado à Sociedade Psicanalítica do Paraná (SPP). Doutor em Filosofia pela Universidade Estadual de Campinas, possui ainda Licenciatura, Bacharelado e Mestrado em Filosofia pela Universidade Federal de Minas Gerais. Professor Adjunto D da Universidade Estadual do Centro-Oeste (Guarapuava/PR), na qual desenvolve pesquisa Continuada (PqC) em torno do problema da metafísica como ciência e como modo de vida na época atual, do pensar na pós-modernidade e da emergência de uma metafísica pós-moderna.

2 Por 'primeira clínica de Lacan' entende-se aqui a clínica fundada no retorno à escuta freudiana, a qual, nessa medida, conforme Jorge Forbes (2014) é revisada e formalizada, instruída por conceitos oriundos da linguística saussuriana, em especial o conceito de significante, cujo papel constitutivo foi reconhecido e assumido como essencial para a fundação da Psicanálise como ciência, em suma, para a articulação simbólica do inconsciente.

${ }^{3}$ Este trabalho utiliza o texto estabelecido por J.-A. Miller em sua primeira edição original (publicada na Coleção Le Champ Freudien), as citações seguem a versão brasileira (Lacan 1985a) de M. D. Magno, em alguns casos, ligeiramente modificada.
} 
da representação (Vorstellungsrepräsentanz) ${ }^{4}$. Uma dialética que, como dialética do conceito, é precisamente a negação do sujeito pelo Outro, que o faz congelar-se em significante (ibid., p. 65 ; p. 181). Este "congelar-se", de certo ponto de vista, não é senão o recalcamento mesmo; algo não tematizado por Lacan, mas ao qual este trabalho pretende constituir uma primeira introdução.

A tese acima referida foi tematizada nas lições II, XII e XVI, as quais discutem - de modo respectivo - o inconsciente, a transferência e a alienação. Tais conceitos são concebidos em Lacan mediante a pressuposição da linguagem e da fala como elementos determinantes do sujeito, mais precisamente do significante como "aquilo que representa um sujeito" (Lacan 1973, p. 180-181), e "não para um outro sujeito", completa o psicanalista, "mas para um outro significante" (ibid., p. 181). Falta discutir, porém, o que Lacan entende pelo termo 'representa' (o presente do indicativo do verbo representar na terceira pessoa do singular); ora, "aquilo que representa", para usar aqui as palavras de Muralt (2008, p. 142), "participa representativamente": isso quer dizer que ele faz as vezes da representação ela mesma. Logo, o significante não representa ou substitui apenas o sujeito, mas também a representação, quando deve ser tomado como representante da representação (Vorstellungsrepräsentanz); em suma, tem que ser considerado, no caso de Lacan, a título de representação (enquanto esta é representada pelo seu representante) e, assim, como algo separado do ser ${ }^{5}$; em termos lacanianos, da vida imortal ou do sujeito cuja emergência no campo do Outro implica a cisão do sujeito, sua alienação (Lacan 1973, p. 179-180; p. 205ss). Em vista disso, a representação permanece reduzida a seu representante, não avança, portanto, a seu representado (à sua significação ou ao seu significado); assim, ela se reduz ao significante, que, como resultado do congelamento do sujeito, é precisamente o recalcado. Situação em que, para representar a representação, ou antes disso congelar o sujeito, o significante/representante teria que ser igualmente "comprimido", "esmagado", "compactado", em outros termos, fixado; não ele mesmo e sim a imagem que nele se congela, algo cuja origem pode ser encontrada nas discussões entre Henrique de Gand e Duns Scotus (Muralt 2008, p. 142-145). Em suma, para o que aqui interessa, conforme a teorização de Lacan (1973, p. 181), de um lado, o sujeito se congela (se fige) em significante, e com isso em representante da representação, da qual ele seria sujeito; de outro, dissolve-se em pulsões, em imagens ${ }^{6}$.

Há aqui duas sortes de cisão: uma, a do sujeito vivente, sexuado, do Real-Ich (eu real) ou do moi (eu), portanto do sujeito determinado pelas pulsões, cisão da qual não se trata neste trabalho; outra, a do sujeito determinado pela linguagem e pela fala, que, por isso, surge precisamente no campo do Outro. Essa a acima designada "cisão do sujeito mesmo", a cisão do "sujeito do inconsciente", do Eu ( $\mathrm{Je})$ : a qual, devido ao congelamento do sujeito (do inconsciente) em significante, em representação (igualmente inconsciente), implica, para o sujeito vivente ou sexuado, a perda à qual ele tem que se reportar e que ele precisa suportar devido sua passagem pelo ciclo sexual; portanto, sua dissolução em

\footnotetext{
${ }^{4}$ Esse termo é usado aqui no sentido de representante da pulsão no domínio da representação, mais especificamente, no sentido do recalcado (Lacan, 1973, p. 198).

${ }^{5}$ Essa questão (da interpretação lacaniana do Vorstellungsrepräsentanz de Freud é toda ela devedora da concepção saussuriana do signo, bem como esta, conforme o mostrara Muralt (2008, p. 51ss; p. 145ss) é devedora da concepção scotiana do ser objetivo (esse objectivum) ou representado, cuja ponto de partida consiste na separação de ser e representação (Boulnois, 1999, passim).

${ }^{6} \mathrm{O}$ termo 'imagens' não é usado nesse contexto por Lacan. Entretanto, o trabalho se vê aí autorizado a utilizá-lo na medida em que, nesse contexto, o psicanalista francês faz referência à concepção freudiana do inconsciente; assim como sua concepção de significante não é senão uma apropriação da formalização estruturalista da imagem mesma.
} 
pulsões, em imagens. Tem-se assim, em parte, o sujeito que nasce e se congela no campo do Outro e, em parte, o sujeito que se dissolve no campo da pulsão; caso em que a perda acima referida não é senão a perda de si mesmo, isto é, do ser-próprio, ou antes, do serpróprio-aí, permanecendo apenas a representação inconsciente do sujeito, ou antes o representante deste, o significante; donde tal representação se mostrar sem ser objetivo ou representado. Destituída de ser objetivo ou, mais bem, de ser-aí (aqui, o ser vivo humano), e assim reduzida ao seu representante, tal representação é vazia, sem objeto, logo sem objetividade, em suma, sem sentido e sem significado ${ }^{7}$. Assim, ela não pode ser senão imagem, mas imagem enquanto imagem não se congela: logo, tal representação não é imagem, mas tão só a forma vazia, o chamado objeto $a$, que representa a vida eterna subtraída ao ser vivo (Lacan 1973, p. 180). Com o que o representante se reduz ao mero formalismo lógico-matemático, típico do estruturalismo linguístico do século $\mathrm{XX}$.

A seguir, o trabalho explicita a proposição "o inconsciente é estruturado como uma linguagem" e sua fundamentação a partir da Antropologia de Lévi-Strauss. Ato contínuo, discute o estatuto do significante como ser concreto e como representação vazia ou indeterminada, destituída de conteúdo ou significado e o da imagem fundante do mesmo, a qual se impõe - nos limites daquela Antropologia - como seu pressuposto essencial. Enfim, considera os limites e as contradições do significante para a tematização e a compreensão do inconsciente.

\section{A tese fundamental de Lacan}

Na segunda seção da Lição II, Lacan (1973, p. 23) enuncia pela primeira vez sua famosa asserção fundante: "o inconsciente é estruturado como uma linguagem". O acento aqui é dado ao artigo indefinido feminino 'uma'; o psicanalista não afirma que o inconsciente é estruturado "como linguagem" ou "como a linguagem" e sim "como uma linguagem". Nesse caso, o termo 'uma' não pode ser lido sem o advérbio que o antecede; 'como' implica aí que o inconsciente não é linguagem, nem a linguagem, nem uma linguagem, mas tão só que é "como" uma linguagem. Implica, pois, que a estrutura do inconsciente não é unívoca, e assim derivada daquela de uma linguagem determinada, mas antes homóloga à estrutura da linguagem mesma; logo, que se conforma no âmbito da práxis (aqui, do ato de fala) e não no de uma teorização divorciada dessa práxis. Contudo, enfim, qual seria o sentido dessa implicação, a homologia implicada seria por sua vez suficiente para responder adequadamente à questão proposta?

Se é o caso de a estrutura do inconsciente mostrar-se homóloga à da linguagem, as duas estruturas serão diversas quanto a seus fundamentos próprios, mas, no entanto, se conformarão como um só e mesmo (homo) logos, isto é, a partir de um logos comum. Porém, a expressão 'como uma' em "o inconsciente é estruturado como uma linguagem" impede qualquer avanço nessa direção; pois, nela, 'linguagem' não é o outro termo homologado ou que se homologa com o inconsciente e sim o termo que indica seu fundamento, seu modelo etc. Se não é o caso de uma homologia, também não poderia ser o de uma univocidade, esta, na situação presente, por implicar a identidade das estruturas em questão, pressupõe aquela como seu ponto de partida concreto, do qual a univocidade e, com ela, a identidade não seriam senão a formalização. Não obstante, Lacan entende o 'como uma' no sentido de uma derivação da estrutura do inconsciente a partir da estrutura da linguagem; partindo, pois, da Linguística estrutural a título de modelo, se lhe torna

\footnotetext{
${ }^{7}$ Sobre esse tema, duas orientações (entre as quais Lacan parece situar-se) se mostram relevantes: de um lado, a fenomenologia (Husserl 2003, passim) e, de outro, a filosofia analítica (Benoist 2001, passim).
} 
necessário investigar a natureza - mais precisamente a estrutura - de um só e mesmo (idem) logos do qual deriva a estrutura do inconsciente. Um só e mesmo (idem) logos que, como tal, se perfaz como a estrutura do signo, composto de significante e de significado, estes - respectivamente - oriundos de uma apropriação do ser concreto da imagem e da função referencial do conceito; esse, em sua origem, a abstração e a fixação da forma real (eidos) atuante naquela . Isso implica de saída, igualmente, a cisão, a descontinuidade, o corte etc., bem como, na base destes, a existência de um continuum: a vida imortal, simplificada (que não precisa de nenhum órgão) e indestrutível (Lacan 1973, p. 180).

Se o inconsciente é estruturado como uma linguagem, no sentido da homologia acima aludida, ele não pode ser uma representação aplicável a um substrato determinado (mesmo pré-ontológico) ou, antes disso, um sujeito que, como tal, exige ser representado objetivamente (isto é, abstratamente) por um dado representante que o representa, não para outro sujeito, mas para outro representante. Lacan (1973, p. 122) reconhece esse fato e, por isso, procura afastar-se das considerações ontológicas (e mesmo epistemológicas), cujas formas, para ele, substantivariam demais o inconsciente; isso é certo, mas também não é o caso de se afirmar que o que é representado (o inconsciente ou, antes, o sujeito do inconsciente), é representado pelo significante para outro significante. Do contrário, o resultado é tão somente a construção teórica de uma estrutura lógica - dita profunda dos processos inconscientes, a qual, embora tenha sua eficácia diagnóstica, como que impede a práxis, permanecendo ambas - aqui, a teoria e a prática psicanalíticas divorciadas; algo característico da concepção moderna de ciência, ela mesma divorciada da vida ou, mais propriamente do mundo da vida. Situação em que a própria vida se mostra cindida de um lado em vida imortal, irrepreensível, privada de órgão, simplificada, indestrutível e, de outro, em ser vivo sexuado (ibid., p. 180).

O inconsciente não é nem mesmo o nome ou a palavra que - como elemento básico da linguagem - representaria o sujeito aludido; porém, como uma linguagem, ele pode ser apreendido e comunicado na medida em que, através de certos símbolos, se manifesta na fala e no agir, mais propriamente na fala enquanto um agir; assim, tal como o pensamento selvagem (na concepção de Lévi-Strauss) - cujo funcionamento é por sua vez entendido por Lacan como "um inconsciente" (Lacan 1973, p. 17) -, antes de qualquer experiência ou dedução individual, certa função classificatória primária ou pré-subjetiva o organiza e lhe dá seu estatuto (ibid., p. 23). Em vista disso, aqueles símbolos e essa função classificatória operam ao nível da natureza, antes de qualquer formação do sujeito enquanto sujeito que pensa, e são desse modo fornecidos por ela enquanto os significantes que, como tais, organizam de modo inaugural as relações humanas, lhes dando as estruturas e as modelando (ibid.). Mas isso implica que o inconsciente é estruturado pelo significante, sendo essa a razão de sua estruturação como uma linguagem; caso em que se exige investigar sua natureza própria.

A tese da homologia - mas não a da identificação - entre o inconsciente e o funcionamento do pensamento selvagem, aludidas mais acima, não são arbitrárias. Malgrado Lacan, que duvida se o "um inconsciente" - posto por Lévi-Strauss na base dos estatutos da sociedade - "será suficiente para albergar" o inconsciente como tal, e, se o for, se "albergará o inconsciente freudiano" (Lacan 1973, p. 17), elas permitem compreender, antes de tudo, a origem do significante, concebido antropológica ou psicanaliticamente, a partir do próprio inconsciente e não a origem deste naquele. Logo, se o inconsciente é estruturado como uma linguagem e se o funcionamento do pensamento selvagem é um inconsciente, então o funcionamento do pensamento selvagem, além de se mostrar como um caso exemplar e, portanto, determinado do inconsciente, é também, necessariamente, estruturado como uma linguagem. Mas, se estaria aqui diante de uma e 
mesma concepção de linguagem, em rigor, de inconsciente estruturado como uma linguagem ou, ao invés, se estaria diante de concepções diversas?

Ora, a linguagem do "um inconsciente" do pensamento selvagem não é senão o totem, que organiza, estrutura e modela as relações dos povos originários em todas as suas dimensões e se configura sob a forma de uma lógica concreta (a lógica das classificações totêmicas) e, por conseguinte, de um pensar em imagens (aqui o pensar mítico). Quanto a esse ponto, é essencial reconhecer o papel fundante da imagem, a um só tempo, tanto no funcionamento do pensamento selvagem, ou mais propriamente mítico, quanto no inconsciente propriamente dito; isso, à diferença da ideia ou do conceito no pensamento abstrato. Esse, ao que parece, assumido por Lacan no conjunto de sua obra e, aqui, nesse ponto, expresso na determinação "como tal" em sua referência ao inconsciente, para distingui-lo do "um inconsciente" do pensamento selvagem e do inconsciente freudiano (Lacan 1973, p. 17). Mas de que imagem se está falando aqui e em que sentido ela se mostra fundante?

Não se trata, nesse ponto, de 'imagem' no sentido - por exemplo - das imagens em jogo no processo da formação imaginária do eu ( $\mathrm{moi}$ ), portanto da imagem especular; trata-se, antes disso, de 'imagem' no sentido de uma forma epistêmica do pensar entendido como um pensar em imagens - homóloga ao ato de pensar (psiquicamente determinado). Lévi-Strauss capta de maneira engenhosa o papel fundante dessa imagem, no pensamento mítico, em um parágrafo magistral de $O$ pensamento selvagem; isso, numa descrição da imagem que, em linhas gerais, faz transparecer certa influência freudiana: por exemplo, quando o fundador da Psicanálise afirma que "o pensar em imagens está mais próximo dos processos inconscientes que o pensar em palavras" (Freud 1923/2011, p. 26), no caso, o pensar conceitual. Que se leiam por inteiro as observações de LéviStrauss (1962, p. 30-31), para em seguida confrontá-las com a concepção lacaniana do inconsciente:

A imagem não pode ser ideia, mas pode cumprir a função de signo, ou, mais exatamente, coabitar com a ideia num signo; e, se a ideia não está aí ainda, pode respeitar-lhe o futuro lugar e fazer aparecer, em negativo, seus contornos. A imagem está congelada, ligada de maneira unívoca ao ato de consciência que a acompanha; mas o signo, e a imagem tornada significante, se eles são ainda sem compreensão, isto é, se lhes faltam ligações, simultânea e teoricamente ilimitadas, com outros seres do mesmo tipo - privilégio do conceito - são já permutáveis, i.é, susceptíveis de manter relações sucessivas com outros seres, se bem que em número limitado, e, como vimos, com a condição de formar sempre um sistema no qual uma modificação que afete um elemento, interessará, automaticamente, a todos os outros: nesse plano, a extensão e a compreensão dos lógicos existem, não como dois aspectos distintos e complementares, mas como realidade solidária. Compreende-se, assim, que o pensamento mítico, se bem que caiado em imagens, já possa ser generalizador, portanto científico: ele trabalha também com lances de analogias e de aproximações, mesmo se, como no caso do bricolage, suas criações se reduzam sempre a um arranjo novo de elementos, cuja natureza não se modifica conforme figurem no conjunto instrumental ou na disposição final (que, exceto pela disposição interna, formam sempre o mesmo conjunto): "dirse-ia que apenas formados, os universos mitológicos se destinam a ser desmantelados para que novos universos nasçam de seus fragmentos" (Boas I, p. 18). Esta observação profunda esquece, entretanto, que, nessa incessante reconstrução, com o auxílio dos mesmos materiais, são sempre os antigos fins 
que são chamados a cumprir a função de meios: os significados tornam-se significantes e inversamente. ${ }^{8}$

É importante destacar, no trecho citado, os seguintes aspectos da imagem: (1) não é ideia, nem conceito, mas cumpre a função de signo; (2) uma vez congelada, liga-se de maneira unívoca ao ato de consciência que a acompanha; (3) tornada significante, embora não possua compreensão (no sentido da lógica tradicional), é susceptível de manter relações sucessivas com outros seres; (4) nesse plano, a extensão e a compreensão "dos lógicos" não conformam dois aspectos distintos e complementares, mas uma realidade solidária; (5) é capaz de generalização, logo de ciência; (6) trabalha com analogias e aproximações, em cujas criações e recriações a natureza dos elementos organizados não se modifica conforme figurem no conjunto instrumental ou na disposição final; (7) nessas criações e recriações, são sempre os antigos fins que são chamados a cumprir a função de meios: os significados tornam-se significantes e inversamente. Considerem-se agora cada um desses aspectos.

Seguindo Saussure, porém tematizando os pressupostos de sua concepção, LéviStrauss distingue imagem, signo e conceito ou ideia e localiza o signo entre estes últimos e aquela, bem como o assume como a ligação ou a união entre uma imagem e um conceito, quando ambos podem coabitá-lo e, assim, desempenhar, de modo respectivo, os papeis de significante e de significado (Lévi-Strauss, 1962, p. 28). Em vista disso, (1) a imagem não pode ser ideia, isto é, significado, no entanto pode cumprir a função de signo: em princípio, desempenha a de significante, contudo, de certo modo, devido (2) ao seu congelamento e à univocidade do ato da consciência que assim a acompanha, cumpre também, ao fim e ao cabo, (7) a de significado; isso porque, como significante ou meio, é chamada a desempenhar a função de fim. Como ser concreto, (3) tornada significante, embora não possua compreensão, ela é susceptível de manter relações sucessivas com outros seres, conformando, pois, com a extensão, (4) não aspectos distintos e complementares, mas uma realidade solidária; torna-se, pois, (5) capaz de generalização, logo de ciência. Ciência concreta, não abstrata, portanto fundada no interesse prático como determinante do teórico e não o contrário; quando, enfim, (6) tal ciência procede conforme analogias e aproximações e não mediante aplicação de conceitos abstratos a substratos materiais por eles então determinados.

Se essa pode ser dita, em linhas gerais, a estrutura do pensamento selvagem conforme Lévi-Strauss, não obstante a dúvida lacaniana acima referida (Lacan 1973, p. 17), ela também poderá ser considerada a estrutura do inconsciente segundo Lacan; algo afirmado pelo próprio psicanalista quando distingue sua concepção de inconsciente daquela de Freud. Isso quando da observação do freudiano francês de que a estrutura que dá seu estatuto ao inconsciente é "o jogo combinatório operando em sua espontaneidade, sozinho, de maneira pré-subjetiva" (ibid., p. 24), que constitui o modelo da Linguística; o que, confrontado com o trecho de Lévi-Strauss mais acima citado e a discussão que o antecede, se mostra problemático. Isso porque a estrutura do funcionamento do pensamento selvagem - que funciona como um inconsciente - se funda no significante enquanto este é uma função desempenhada pela imagem; a qual, justamente por também por cumprir a função de significado, funda a linguagem, isto é, o totem. Ao contrário, no inconsciente lacanianao, o significante se mostra como seu elemento fundante na medida em que o permite dizer-se, em rigor, estruturar-se segundo o modelo de uma linguagem; a qual não é senão a estrutura mesma conformada de significante e de significado. No pensamento selvagem só há significante se este é plasmado pela imagem, embora isto

\footnotetext{
${ }^{8}$ Citado conforme Lévi-Strauss 1976, p. 41-42, com ligeiras modificações.
} 
ocorra tão só porquanto ela habita o signo, ou antes o coabita com a ideia, sendo a imagem - tomada enquanto fundante - anterior ao signo e, portanto, ao significante. Enfim, no pensamento lacaniano, fundado na Linguística, deve haver "sob o termo de inconsciente algo de qualificável, de acessível, de objetivável” (ibid., p. 24), isto é, o significante assumido como dado positivo.

Com "algo de qualificável, de acessível, de objetivável”, Lacan parece querer dizer precisamente o que na tradição da metafísica moderna se designara ser objetivo ou representado e realidade objetiva de uma ideia. Uma tradição que, epistemicamente, se inicia com Duns Scotus (nos séculos XIII-XIV), passa por Descartes, e segue até a filosofia analítica da linguagem, já na segunda metade do século $\mathrm{XX}^{9}$; tradição da qual, de modo alvissareiro, Freud se desvia e faz o caminho inverso - ainda que, em alguns casos, utilizando-se de termos filosóficos tipicamente modernos -, por exemplo, quando afirma que o inconsciente é um conceito dinâmico. Essa a afirmação duramente criticada e, em consequência, rejeitada por Lacan (Lacan 1973, p. 24).

\section{O estatuto do significante}

Se o funcionamento do pensamento selvagem é um inconsciente, ou seja, um caso exemplar e determinado do inconsciente, bem como, por isso, estruturado como uma linguagem, o totem, portanto fundada em imagens; então, porquanto o inconsciente consiste essencialmente nessas imagens, é ele quem estrutura o significante e a linguagem e não o contrário. Se é o significante, ao invés, o elemento estruturante do inconsciente logo do funcionamento do pensamento selvagem -, organizando, pois, de modo inaugural as relações humanas, sendo, por conseguinte, anterior ao sujeito e constituinte deste; qual seria, enfim, a estrutura do próprio significante?

Enquanto elemento estruturante do inconsciente e, por isso, do pensamento selvagem, os quais se mostrariam estruturados como uma linguagem, o significante não pode ser concebido senão como o elemento estruturante da própria linguagem; assim, perguntar-se pela estrutura do significante é perguntar-se igualmente pela estrutura da própria linguagem. Ora, conforme Lacan, na Lição XVI, a estrutura do inconsciente compõe-se de dois campos, o campo do sujeito e o campo do Outro; esse "o lugar em que se situa a cadeia do significante que comanda tudo que vai poder presentificar-se do sujeito, é o campo desse vivo onde o sujeito tem que aparecer" (Lacan 1973, p. 185), o campo em que a pulsão se manifesta essencialmente. Em vista disso, a estrutura do significante se mostra como o corte, a descontinuidade, a fenda, a ruptura ou a hiância do sujeito e do Outro, em rigor, a hiância do inconsciente; sendo a função do corte o fundamento da referida estrutura (ibid., p. 188), e o corte mesmo aquilo que faz surgir a ausência, a falta, essa cujo conceito, como conceito da falta ou "inconceito" (Unbegriff), que não é o não-conceito, é o limite do inconsciente (Unbewusste) (ibid., p. 28). Por isso, na Lição IV, Lacan afirma que a verdadeira função do conceito do Unbewusste é estar em relação profunda, inicial, inaugural, com a do conceito de Unbegriff - ou do Begriff do Un (o conceito do in) original, isto é, o corte. Esse, por sua vez, ligado profundamente à função do sujeito como tal, do sujeito em sua relação constituinte do próprio significante (ibid., p. 44).

\footnotetext{
${ }^{9}$ Essa a tematiza desenvolvida por Muralt (2008, p. 42ss; p. 145ss; p. 184-202) no tocante à teoría do conhecimento; a qual, em diversos pontos, tangencia com a linguística saussuriana e a psicanálise nela fundada, aqui distinguida da de Freud (Muralt, 2008, p. 51ss; p. 178), algo que se pode confrontar no próprio Saussure (1949, p. 97-100).
} 
Embora engenhosa, a inversão de Lacan (de Unbegriff para Begriff do Un) produz um problema incomensurável. Seu engenho consiste em reconhecer que o Un (in) de Unbegriff (inconceito) e o de Unbewusste (inconsciente) dizem o mesmo, logo o idêntico; razão pela qual, ao interpretar o Un (in) como falta, ausência e, portanto, - para lembrar Aristóteles -, como privação, o psicanalista acerta ao afirmar que o Unbegriff não é o não-conceito, ou a mera negação do conceito. Porém, ao dizer que o Unbegriffé o conceito da falta ou do in $(U n)$ - em suma, da privação - original, ele determina o indeterminado ou antes o indeterminável e assim positiva o inconsciente, substantivandoo mais do que pretendia (Lacan 1973, p. 122). Nessa medida, seu procedimento filia-se àquele de Hegel, que, no início de sua Lógica, toma como determinidade justamente a indeterminidade do ser livre de determinidade e, com isso, o assume como ser puro como o conceito em si -, considerado vazio (a um tempo como ser e nada puros) pelo fato de nele nada haver para ser pensado ou intuído; caso em que o pensar e o intuir aí em jogo são igualmente puros e, assim, puro ser e puro nada (Hegel 1969a, p. 82ss). Com esse procedimento, Hegel pretende demonstrar a seguinte proposição: "Nada intuir ou pensar tem, portanto, um significado; ambos são distintos; assim é (existe) Nada em nosso intuir ou pensar; ou antes, é o intuir vazio e o pensar vazio mesmo e o mesmo intuir vazio ou pensar vazio como o ser puro" (ibid., p. 83); ao que parece, Lacan segue o mesmo procedimento, ou deste se aproxima perigosamente. Quer dizer, se o Unbegriff é o Begriff do Un original, isto é, o corte, ele é propriamente negação desse Un; contudo, tal como apresentado por Lacan, ele se mostra como posição do corte ou como o próprio corte, isto é, como a posição da fissura no Um mesmo, e como a assunção desta enquanto una. Em vista disso, o Unbegriff termina por transformar-se em Inbegriff (o que permitiria outro uso de 'inconceito' para traduzir Unbegriff), entendendo-se aqui, por Inbegriff, nada mais que o conceito-integrativo, e, por excelência, o conceito-integrativo de todas as realidades que, como tal, refere-se a uma multiplicidade concreta, mas que, assim, como observara Hegel (1969b, p. 14), se reduz a uma simplicidade vazia. Na medida em que é o corte que faz surgir a ausência, a falta - e porquanto o conceito desta é o Unbegriff, tomado como o próprio corte -, a falta, a ausência, não poderá ser senão o Un em questão; o qual é negativo do ponto de vista do conhecimento, mas positivo no sentido de fazer algo vir à existência, ainda que esta seja a marca do vazio daquele, uma existência destituída de substância: pura e simples "ec-sistência”. Quando Lacan (1973, p. 117; p. 122) não pode não reconhecer certa influência neoplatônica, precisamente em relação à presença do analista enquanto manifestação do inconsciente, em resposta à Jean Wahl, no que toca à definição da causa inconsciente; a qual não é nem um ente (ov), nem um não-ente $(o v \chi o v)$, mas um não-realizado, em rigor, não-realizável, em suma, uma faltaem-ser, mais bem, um des-ser $(\mu \eta o v)^{10}$. O problema que aqui se impõe é o fato de se apor categorias e formas de pensamento a essa falta-em-ser ou a esse des-ser, as quais terminam por aprisiona-lo e torna-lo mero vestígio de um vestígio.

Ao invés da interpretação do Unbegriff acima tematizada, aquela aludida mais acima - negada por Lacan - implica reconhecer uma dimensão anterior ao conceito, e portanto à ideia, uma dimensão que, como tal, não se reduz a estes, mas que aos mesmos se mantém dialeticamente oposta e com eles se relaciona apenas quando a eles se une na coabitação do signo. Essa a dimensão do Unbegriff enquanto não-conceito, que não é mera negação do conceito, mas o inconceito propriamente dito, ou antes o inconcebível, cujo in (Un) é precisamente o in (Un) do informe (Unform), que, portanto, conforme a intuição mesma de Lacan, é e permanece pré-ontológico se, e somente se, por ontológico

${ }^{10}$ Sobre esse ponto seria interessante ver Lacan 1998 (p. 596/589), assim como o comentário de Gabas 2010 (p. 168). 
se entender a justaposição de categorias ou formas lógicas ao ser mesmo ou ao ser-aí. Estes, neles mesmos, são privados de categorias e formas abstratas, ou determinações estruturais a priori, sua ec-sistência no informe (Unform), no inconsciente (Unbewusste) ou no inconceito (Unbegriff) manifesta a própria cisão, o corte, a descontinuidade da forma (Form), do consciente (Bewusste) ou do conceito (Begriff); o que é inapreensível por estes enquanto eles permanecem na abstração. Eis o que justifica uma afirmação de Blumenberg (2013, p. 129), referida a Freud, segundo a qual a vida onírica não conhece a negação (diríamos a privação ou a falta), porque o sonho não conhece conceitos.

Mesmo Saussure e Lévi-Strauss, ainda que em parte, parecem concordar com essa assertiva; isso na medida em que partem de uma mesma concepção acerca do signo. Sobre este ponto é digno de nota o que afirma Saussure (1949, p. 98):

\begin{abstract}
O signo linguístico une não uma coisa e um nome, mas um conceito e uma imagem acústica. Esta última não é o som material, coisa puramente física, mas a impressão psíquica deste som, a representação que nos dá o testemunho dos nossos sentidos; ela é sensorial, e se chegamos a chamá-la 'material' é somente no sentido e por oposição ao outro termo da associação, o conceito, geralmente mais abstrato.
\end{abstract}

O que mais importa aqui, fazendo-se abstração da concepção saussuriana de imagem ${ }^{11}$, é o reconhecimento do caráter 'material', portanto concreto e movente da imagem em oposição ao aspecto formal e abstrato, logo imóvel, do conceito. Oposição que funda a natureza dupla, dúplice ou antes ambígua do signo linguístico, ele próprio entendido como "uma entidade psíquica de duas faces", a qual, nela mesma, se mostra um todo constituído de imagem acústica e de conceito, os quais, por sua vez, no signo, enquanto as faces deste, se apresentam respectivamente como significante e como significado (Saussure 1949, p. 99-100). Isso implica que a emergência do significante só é possível porquanto (1) se faça a distinção entre imagem (no sentido em que este trabalho designa fundante) e signo e (2) se submeta a este aquela, transformando-a - mediante seu "congelamento" (figée), como afirma Lévi-Strauss - em significante ${ }^{12}$. Ora, o que "congela" a imagem - ou dela retira seu caráter movente ou dinâmico - é precisamente o conceito abstrato; o qual, porque fixo e vazio, ou destituído de 'matéria', só pode mostrarse (no signo) como o ser representado (objetivo) da imagem assim congelada, enquanto representada fixamente, como que uma fotografia de um momento dado do real: eis aí o significado, travestido de significante, de representante da representação. Não admira Lacan falar em alienação e em congelamento do sujeito; isso aumenta o paradoxo de sua tentativa de "restituição do sujeito ao seu lugar de origem".

Esse "lugar de origem do sujeito" é designado por Lacan (1973, p. 45) "o lugar completo, total, da rede dos significantes, o sujeito, lá onde estava, desde sempre, o sonho"; este, ainda conforme Lacan, o lugar da certeza, posta por Freud unicamente na "constelação dos significantes, tal como eles resultam na narrativa, do comentário, da associação, pouco importando a retratação" (ibid.) de uma mente supostamente consciente ou de um eu penso certo de si mesmo apreendido no eu duvido, tal qual aquele da certeza cartesiana. Se isto é assim e se o Unbegriff é mesmo o limite do Unbewusste, ao invés de se falar de conceito do "Un" original (Begriff de l'Un originel), a saber, o corte (la coupure) ou de conceito da falta (ibid., p. 28) (concept du manque), dever-se-ia

\footnotetext{
${ }^{11}$ Sobre este ponto, ver nota dos editores em Saussure 1949, p. 98, bem como as próprias observações de Saussure às páginas seguintes.

12 Eis o procedimento apropriado por Lacan (1973, p. 181), para quem o sujeito, ao nascer no campo do Outro, "se congela (fige) em significante".
} 
dizer precisamente conceito do não (da negação, do recalque ou, ainda, do retorno do recalcado) original; pois, se se levar a sério o Unbegriff como limite do Unbewusste, e, portanto, como conceito da falta, há que se reconhecer o Unbewusste precisamente como a falta do conceito e o Unbegriff como o conceito que falta. Se o "Un" (do Unbegriff) enquanto corte é a entrada ou a abertura do inconsciente, sendo o corte o próprio significante, então esse "Un" tem que ser necessariamente o "um" do "sign-um", que, linguisticamente interpretado, de modo algum é um, mas dois, sendo seu "um" a marca de sua dilaceração "signica" na medida em que ele, como signo linguístico, impõe à imagem os ditames do conceito, a negação. O signo linguístico ele mesmo emerge apenas quando da cisão originária do "Sign-Um", ou do "Si(g)n-al”, do Todo que é (ou indica) o Um e do Um que é (ou indica) o Todo; em suma, daquilo que os antigos designavam 'katholou' - de modo nen(h)-um o universal abstrato da tradição da metafísica da representação, mas o que, enquanto concreto, é portanto com(o)-um a/em todos os singulares ${ }^{13}$.

Com a restituição do Eu, isto é, do sujeito e não da Psicologia, lá onde ele estava - antes da dissociação cartesiana -, por conseguinte ao campo do sonho, conforme o lema Wo es war, soll Ich werden (Lá onde estava, devo tornar), ou segundo Lacan: Aqui, no campo do sonho, estás em casa, isso significa, enfim, que Freud dissolve a distinção cartesiana de sujeito e função psíquica, de corpo e alma etc., bem como as distinções da filosofia moderna posteriores a Descartes, em especial a distinção entre teoria e práxis. Se isto é assim, a interpretação lacaniana (ou, poder-se-ia dizer estruturalista) dessa dissolução implica precisamente o seu contrário e a restituição daquela dissociação, agora no plano formal de sua unidade "signica", que aliena e congela o sujeito, ou antes, a imagem em significante; o que não é senão a subordinação dos primeiros à função referencial do último na medida em que, no signo, como unidade de imagem e conceito, de ser concreto e de função referencial, esta, assim como o conceito, dado que é função do conceito mesmo, termina por se impor àquele e, com isso, à imagem. Eis o que a congela e, com isso, aliena e congela o sujeito.

Um sujeito congelado em significante é "unbewussten Subjektes", mas este é propriamente Un-bewusste; em rigor, o Um-sabido que - para a consciência (a qual se limita a representar e, assim, a transformar imagens em significantes) ou para o conceito - é sempre e necessariamente o Não-sabido. Não o que não é sabido (das Bewusstlose), como o "só sei que nada sei" de Sócrates, mas o que é sabido como Não ou, no limite, como Nada; logo, um saber do Todo ou do Um que, assim, é antes de tudo indeterminado, que nada tem de determinado, de teórico ou de qualitativo - em suma, categorial -, mas um saber livre de determinação categorial ou conceitual, logo prático, cujo ser concreto se dá a conhecer precisamente aí, no ato de fala, no dizer que é fazer. Eis o saber da angústia (esse saber-se suspenso no Nada), que, ilimitado, só se sabe como limite, como a linha na qual o sujeito se equilibra, mas que não se realiza como limitação do ilimitado.

\section{Nota: O sujeito, o significante e o problema da significação}

Lacan reconhece haver uma materialização intransitiva do significante para o significado, a qual ele denomina inconsciente, que, para o freudiano, não é ancoradouro, mas depósito, aluvião da linguagem (Lacan 2003a, p. 415/417). A referida materialização, em outro contexto, foi designada precisamente como a sobredeterminação, quer dizer, "a estrutura que une o significante ao significado na linguagem" (Lacan 2003b, 147/141).

\footnotetext{
${ }^{13}$ Sigo aqui à interpretação de Philip Merlan (1975, p. 173) sobre o Katholou em Aristóteles.
} 
Ora, nesse caso, por que tal materialização seria inconsciente? Os trechos abaixo citados podem iluminar um pouco essa questão:

O significante produzindo-se no campo do Outro faz surgir o sujeito de sua significação. Mas ele só funciona como significante reduzindo o sujeito em instância a não ser mais do que um significante, petrificando-o pelo mesmo movimento com que o chama a funcionar, a falar, como sujeito. Aí está propriamente a pulsação temporal em que se institui o que é a característica da partida do inconsciente como tal - o fechamento. (Lacan 1973, p. 188-189).

A relação entre significante e significado está inteiramente incluída na própria ordem da linguagem, que condiciona integralmente seus dois termos. (Lacan 2003b, p. 154/148).

[...] dizemos que o desejo, seja ele do sonho ou da vigília, não é articulável na fala. Mas nem por isso é verdade que ele não seja articulado na linguagem e que, deslizando como o anel do jogo do passa-anel pelo fio da metonímia que o retém num círculo de fantasia, não produza metaforicamente o significado do sintoma em que essa fantasia se realiza. (Lacan 2003c, p. 179/171).

No primeiro trecho está em jogo o fato de o sujeito nascer no exato momento em que, no campo do Outro, surge o significante. Para nascer, o sujeito tem que falar; ao falar, ele produz o significante e se torna, então, o sujeito de sua significação na medida em que o determina. Desse modo, porém, o sujeito se petrifica, se congela em significante porquanto este emerge no campo do Outro.

Isso implica que o sujeito, in initio, comece no campo do Outro pelo fato de ser neste que primeiro surge o significante, do qual o sujeito depende para que seja sujeito de uma significação; em suma, que se realize enquanto significante. Não obstante, o sujeito pode se pôr sob um ou outro significante, ocupando assim diversos lugares na cadeia de significantes, como tal, designada pela interpretação, a qual, por esse motivo, não se dobra a todos os sentidos (Lacan 1973, p. 189); em acréscimo, há que se lembrar o fato de que o significante, enquanto tal, isto é, destituído ou esvaziado de significado, logo, enquanto se diferencia deste, não significa nada (Lacan 1985b, 210ss; 2003a, p. 401/404). No entanto, se o significante não significa nada, de onde surge o significado, ou antes, o sentido, de um lado, e, de outro, a significação? (Lacan 2003b, p. 155-156/149-150)

Ora, Lacan afirma caracterizar a palavra e a fala na linguagem. Em vista disso, o que está em jogo nos dois últimos trechos, citados acima, é justamente a substituição combinatória do significante e a transubjetividade fundamental do significado. Disso se depreende que algo como o sentido, o significado ou a significação não advém da substituição combinatória do significante, no caso, da palavra ou da fala nas quais este se manifesta, mas, antes, emerge da transubjetividade fundamental do significado enquanto este se dá na linguagem, articulando assim o desejo e produzindo-se como significado do sintoma em que a respectiva fantasia se realiza. Se isso é assim, embora o funcionamento do significante não seja e não possa ser a significação do significante ele mesmo, uma significação pode ser o caso mediante a petrificação do sujeito que produz o significante: ao petrificar-se ou congelar-se em significante, em rigor, o sujeito deixa o campo da fala (o imaginário) e traslada-se imediatamente ao da linguagem (o simbólico), na medida em que esta, à diferença da fala, sempre significa algo naquilo que ela comunica (Lacan 2003 b, p. 154/148). Em vista disso, é por intermédio daquela petrificação do sujeito em significante que este se mostra, em última análise, sobredeterminado e, assim, adquire uma significação cujo sujeito é ele mesmo sobredeterminado pela ambiguidade inerente ao discurso (Lacan 2003c, p. 175-176/167/168). Este, porém, será forçosamente um 
outro, ou antes, o outro sujeito, o sujeito em seu nascimento, o "sujeito vivo", como o "sujeito no campo da pulsão", não "o sujeito tal como ele se evoca no campo do Outro" (Lacan 1973, p. 181; p. 185ss); este o sujeito que, conforme a apelação de Lacan (1973, p. 191), para livrar-se da condenação e da consequente alienação de "só se ver surgir in initio no campo do Outro", tem que dissolver sua petrificação em significante e, com isso, não mais referi-lo a um significado determinado, que portanto o sobredetermina. Cônscio desse problema, Lacan refugiara-se no pensamento mítico; porém, não conferiu a tal pensamento seu estatuto de um pensamento independente e rigoroso.

Lacan permanece na apelação e faz as vezes do sujeito que se evoca no campo do Outro e que, assim, se condena a só se ver surgir, in initio, neste campo (Lacan 1973, p. 191). Isso ocorre porque, no âmbito da produção e do funcionamento do significante e da significação, o psicanalista rebaixa a imagem própria do significante em relação à representação do significado ou do sentido, que ele afirma porquanto pretende fundar uma topologia e uma álgebra; bem como pelo fato de utilizar-se da representação mítica, mas em reduzindo-a ao imaginário, apenas para interpretar a libido. Essa considerada um órgão irreal, mas de modo algum imaginário, pois o irreal se definiria "por se articular ao real de um modo que nos escapa" e na medida em que é isso "justamente o que exige que sua representação seja mítica" (Lacan 1973, p. 187). Se isso é assim, não será porque, com a imposição de uma lógica, ou antes de uma topologia, e de uma álgebra sobre os fenômenos do inconsciente e, em rigor, sobre o significante, o francês não introduziu, por outros meios, os próprios significados e a ligação formalista de significado e significante da qual ele mesmo, outrora, constatara a ruptura? Por que tal articulação nos escapa e em que medida ela nos escapa?

\section{IV. À guisa de conclusão}

A tese de que "o inconsciente é estruturado como uma linguagem" se mostra essencial não só pra Lacan, mas também e principalmente para Freud; este, contudo, não a elaborou. Entretanto, as concepções de inconsciente e de linguagem são distintas em cada caso; uma distinção que se origina com a rejeição lacaniana dos assim chamados "conceitos introduzidos historicamente por Freud sob o termo inconsciente" (Lacan 1973, p. 24). Embora se incline a distinguir o que seria o inconsciente freudiano em relação a tais conceitos, Lacan reconhece e portanto evoca apenas uma dimensão desse inconsciente, a saber, o domínio da causa; no qual ele pode introduzir o que considera a lei do significante, precisamente no lugar em que a hiância se produz (ibid., p. 26). Em suma, com a lei do significante, o francês pretende reinterpretar aquilo que Freud encontra no buraco, na fenda, na hiância característica da causa; para Lacan, "algo da ordem do não-realizado" (ibid., p. 25-26), que se tornará mais propriamente algo da ordem do "nãorealizável".

É importante reconhecer que o inconsciente freudiano não é o lacaniano. Neste houve a introdução da lei do significante como elemento explicativo do processo causal; reconheceu-se, pois, uma causalidade passível de determinação formal - mediante o modelo fornecido pela Linguística -, e por isso de ordem explicativa. Interpretou-se corretamente a descontinuidade - na qual alguma coisa se manifesta como vacilação como a forma essencial do inconsciente enquanto fenômeno, bem como se localizou de modo igualmente correto o Um, aqui o "Un" do Unbewusste, como posterior a essa descontinuidade (Lacan 1973, p. 28); mas se manteve na cisão da descontinuidade como fenômeno e da cadeia de significantes como elemento a uma vez causal e explicativo. Com isso se manteve a distinção moderna de teoria e prática: no caso, do estatuto 
epistemológico da Psicanálise como ciência e do estatuto ético do inconsciente; em suma, a distinção entre forma e conteúdo. Não parece que Freud tenha se mantido nessa dicotomia, mesmo quando em diálogo com os modernos ou enquanto se apropriando de conceitos e de termos do pensamento moderno.

Na medida em que não pensa a partir do significante, ou da lei deste, Freud elabora sua concepção do inconsciente conforme um ponto de vista distinto da relação entre imagem e conceito; uma relação na qual o signo não se faz linguístico e, portanto, não subordina a imagem ao conceito. Por isso, em A interpretação dos sonhos, o pai da Psicanálise pode afirmar que embora o característico do estado de vigília seja que "a atividade do pensamento aconteça (vor sich geht) em conceitos e não em imagens (...), o sonho pensa principalmente em imagens" (Freud 1900/1961, p. 51ss). Os conceitos, para Freud, se constituem de representações voluntárias e intencionais que, ao se aproximar o momento do sono, se mostram dificultadas ou mesmo incapacitadas e cedem lugar às representações involuntárias, que pertencem todas à classe das imagens (que não são representações em sentido próprio), por sua vez regularmente associadas com a dispersão. Têm-se aqui duas características essenciais do sonho e, também, por conseguinte, do inconsciente; isso implica que os conteúdos destes sejam conteúdos atualmente presentes à psique - experienciados ou vivenciados psiquicamente - que ela, de algum modo, faz vir à tona, os quais a ela, no entanto, só se manifestam no estado de sono ou em atos falhos etc., dado que, no estado de vigília, são negados, em rigor, recalcados ou reprimidos. Em todo caso, são estes conteúdos que permitem a Freud afirmar que não há descontinuidade da vida psíquica, mesmo constituindo eles próprios o fenômeno que o pensamento conceitual designa como lacuna ou descontinuidade.

Ora, ao delimitar o fenômeno da hiância ou da descontinuidade, Lacan deu uma contribuição inestimável para a compreensão do inconsciente freudiano. Não obstante, ao introduzir naquela hiância a lei do significante, o francês pretendeu explicar o fenômeno em questão sobrepondo-lhe uma lei positiva, que, como tal, separa a esfera do fenômeno da esfera de sua essência, reproduzindo assim o fenomenismo moderno, ainda que sob o prisma da linguística estrutural do século XX, sem se dar conta de que nessa própria linguística tanto fenomenismo quanto historicismo já estavam superados. O fato é que a tentativa lacaniana de constituir uma ciência do inconsciente a partir da lei do significante e, portanto, de deduzir de sua tese fundamental uma topologia cuja tarefa seria dar conta da constituição do sujeito, não pode senão soçobrar sob o paradigma de uma ciência teórica, baseada no progresso (Lacan 1976). Resta ao psicanalista francês o estatuto ético do inconsciente, mas aqui, para ele, não é mais a ciência teórica do inconsciente que está em questão e sim uma ciência concebida praticamente. Essa que irá se descortinar apenas quando de seu último ensinamento.

Porque delimita o fenômeno da hiância, e assim contribui de modo inestimável para a compreensão teórica do inconsciente, a obra inicial de Lacan tem que ser assumida como uma premissa fundamental do trabalho analítico. Entretanto, se a fundação da Psicanálise (como ciência teórica) sob a lei do significante soçobra e se a tese de que "o inconsciente é estruturado como uma linguagem" também se mostra essencial para Freud, que, no entanto, não a elaborou, uma via permanece aberta. Essa a perspectiva fundada na própria práxis psicanalítica, da qual Freud ele mesmo jamais se cansou de falar.

\section{Referências}

\section{a) Livros}


Benoist, Jocelyn 2001: Représentations sans objet. Aux origins de la phénoménologie et de la philosophie analytique. Paris: PUF.

Blumenberg, Hans 2013: Teoria da não conceitualidade. Tradução e introdução de Luiz Costa Lima. Belo Horizonte: Editora UFMG.

Boulnois, Olivier 1999: Être et representation. Paris: PUF.

Cabas, Antonio Godino 2010: O Sujeito da Psicanálise de Freud a Lacan: da questão do sujeito ao sujeito em questão. Rio de Janeiro: Zahar.

Hegel, Georg Wilhelm Friedrich 1969b: Werke 6. Wissenschaft der Logik, II. Erster Teil. Die objektive Logik, zweites Buch; zweiter Teil. Die subjektive Logik. Frankfurt am Main: Suhrkamp.

Hegel, Georg Wilhelm Friedrich 1969a: Werke 5. Wissenschaft der Logik, I. Erster Teil. Die objektive Logik. Erstes Buch. Frankfurt am Main: Suhrkamp.

Husserl, Edmund 2003: La représentation vide. Sous a direction de J. Benoist et J.-F. Courtine. Paris: PUF.

Lévi-Strauss, Claude 1976: O pensamento selvagem. Tradução de Maria C. da Costa e Souza, e Almir de Oliveira Aguiar. - 2. Ed. - São Paulo: Companhia Editora Nacional.

Lévi-Strauss, Claude 1962: La pensée sauvage. Paris: Plon.

Merlan, Philip 1975: From Platonism to Neoplatonism, 3. edition, rev, Hague: Martinus Nijhof.

Muralt, André de 2008: La apuesta de la filosofia medieval. Estudios tomistas, escotistas ockmistas y gregorianos. Madrid: Marcial Pons.

Saussure, Ferdinand de 1949: Cours de Linguistique générale. Publié par C. Bally et A. Sechehaye, avec collaboration de A. Riedlinger. Quatrième édition. Paris: Payot.

\section{b) Capítulos ou artigos de livros.}

Forbes, Jorge 2014: “A análise lacaniana hoje: ingredientes, indicações e modos de usar". In Forbes, Jorge (ed.) e Riolfi, Cláudia (org.) 2014: Psicanálise: a clínica do Real. São Paulo: Manole.

\section{c) Obras de Freud}

Freud, Sigmund 2011: “O Eu e o Id”. In Obras completas (Paulo César de Souza, trad., vol. 16, pp. 13-74). São Paulo: Companhia das Letras. (Trabalho original publicado em 1923).

Freud, Sigmund 1961: “Die Traumdeutung”. In Gesammelte Werke (Dritte Auflage, vol. II-III, pp. V-635). London: Imago Publishing; Frankfurt am Main: Fischer Verlag. (Trabalho original publicado em 1900).

\section{d) Obras de Lacan}

Lacan, Jacques 2003a: "Radiofonia". In Lacan, Jacques 2003: Outros escritos. Tradução de Vera Ribeiro. Rio de Janeiro: Jorge Zahar Editor. (Trabalho original publicado em 2001). 
Lacan, Jacques 2003b: "Discurso de Roma". In Lacan, Jacques 2003: Outros escritos. Tradução de Vera Ribeiro. Rio de Janeiro: Jorge Zahar Editor. (Trabalho original publicado em 2001).

Lacan, Jacques 2003c: “A psicanálise verdadeira e a falsa”. In Lacan, Jacques 2003: Outros escritos. Tradução de Vera Ribeiro. Rio de Janeiro: Jorge Zahar Editor. (Trabalho original publicado em 2001).

Lacan, Jacques 1998: “A direção do tratamento e os princípios de seu poder”. In Lacan, Jacques 1998. Escritos. Tradução de Vera Ribeiro. Rio de Janeiro: Jorge Zahar Editor. (Trabalho original publicado em 1958).

Lacan, Jacques 1985a: O Seminário 11. Os quatro conceitos fundamentais da Psicanálise (1964). Trad. M. D. Magno. 2. Ed. Rio de janeiro: Jorge Zahar Editor. (Trabalho original publicado em 1973).

Lacan, Jacques 1985b: O Seminário. 3. As Psicoses (1955-1956). Texto estabelecido por Jacques-Alain Miller. Tradução de Aluísio Pereira de Menezes. Rio de Janeiro: Jorge Zahar Editor. (Trabalho original publicado em 1981).

Lacan, Jacques 1973: Le Séminaire, Livre XI. Les quatre concepts fondamentaux de la psychanalyse (1964). Texte établi par J.-A. Miller. Paris: Éditions du Seuil. (Trabalho original publicado em 1973).

\section{e) Artigo de revista.}

Vorsatz, Ingrid 2015: “O sujeito da psicanálise e o sujeito da ciência: Descartes, Freud e Lacan”. Psicologia Clínica, Rio de Janeiro, vol. 27, n. 2, pp. 249-273.

\section{f) Documentos em meio eletrônico}

Lacan, Jacques 1976: "Séance du 14 décembre 1976 / sesión del 14 de diciembre de 1976”. In Lacan, Jacques 1976-1977: L'insu que sait de l'une-bévue s'aile à mourre (1976-1977). [Bilingüe]. Edición basada en la versión D'après Jacques Lacan, publicada en la revista L'UNEBÉVUE 21 (2003-2004), cotejada con el audio de Lacan. Traducción de Graciela Leguizamón, María del Carmen Melegatti y Rafael Perez. Recuperado em 22 de junho de 2018 da Ecole-lacanienne. Disponível em: http://ecole-lacanienne.net/wpcontent/uploads/2016/04/14-12-76-linsu.pdf. 